\title{
THE GROWTH IN SCIENTIFIC PRODUCTION
}

Dear readers and collaborators,

Those who follow the history of Acta Ortopédica Brasileira know its laborious way to remain in the excellence of the scientific quality deserved by Brazilian researchers in the field of orthopedics. This path is marked by exceptional fruits, merit of the expeditious editorial board and dedicated authors.

For this year, which is about to end, it is extremely relevant to highlight the exponential increase in scientific editorial production. Although atypical, this year also had some favorable points, considering the arid context we live in, which surprisingly boosted the fields of science.

The time imposed by social isolation proved to be fertile in the field of scientific production. We got those pending projects "off the drawing board," making the productivity of medical researchers admirable in recent months. The sending of manuscripts for publication in Acta Ortopédica Brasileira doubled, we still had the largest number of accesses in the last 2 years with almost 110,000 readers in last April. We can only hope the good fruits will remain.

As this change in the scientific scenario is unprecedented, requiring constant evolutionary adaptation in the digital environment, we will bring beneficial changes to our researchers, to be disclosed in the editorials of 2021. Here is the new edition -5 v.28, enjoy!

\section{Professor Olavo Pires de Camargo ${ }^{1}$ (1) \\ Editor-in-Chief \\ Acta Ortopédica Brasileira}

1. Universidade de São Paulo, Medical School, Orthopedics and Traumatology Department (DOT-FMUSP),

São Paulo, SP, Brazil. 